\title{
Bioecology and management of giant African snail, Achatina fulica (Bowdich)
}

\author{
BADAL BHATTACHARYYA*1, MRINMOY DAS ${ }^{1}$, HIMANGSHU MISHRA ${ }^{1}$, D.J. NATH ${ }^{2}$ AND SUDHANSU \\ BHAGAWATI ${ }^{1}$
}

${ }^{1}$ Department of Entomology, Assam Agricultural University, JORHAT (ASSAM) INDIA

${ }^{2}$ Department of Soil Science, Assam Agricultural University, JORHAT (ASSAM) INDIA

\section{ARITCLE INFO \\ Received : 30.06 .2014 \\ Accepted : 21.09 .2014}

\section{KEY WORDS :}

Bioecology, Management, Giant African snail, Achatina fulica
*Corresponding author:

Email: badalassam@aau.ac.in

\begin{abstract}
Giant African snail (Achatina fulica Bowdich) belongs to the Phylum-Mollusca and ClassGastropoda. It is known for its destructive nature on cultivated crops wherever it occurs and is one of the world's largest and most damaging land snail pests. The pest is an East African origin, has spread in recent times by travel and trade to many countries. They now widely distributed and no longer limited to their region of origin due to several factors viz., high reproductive capacity, voracious feeding habit, inadequate quarantine management and human aided dispersal. A. fulica can cause serious economic damage on different crops and extensive rasping (scrapping), defoliation, slime trials, or ribbon like excrement is signs of infestation. In recent times, severe outbreak of this pest has been noticed due to some desirable agricultural and gardening practices like minimum tillage practices and straw retention techniques which help in survival of snails and make seedlings more susceptible to damage. This review paper aims to enlighten on taxonomy, distribution, extent of damage, morphology, biology, ecology, homing behaviour, seasonal incidence, nature of damage, host plants of A. fulica and its ecofriendly management strategies.
\end{abstract}

How to view point the article : Bhattacharyya, Badal, Das, Mrinmoy, Mishra, Himangshu, Nath, D.J. and Bhagawati, Sudansu (2014). Bioecology and management of giant African snail, Achatina fulica (Bowdich). J. Plant Protec., 7(2) : 476-481. 